\title{
The role of inflammation in adipocytolytic nonsurgical esthetic procedures for body contouring
}

\author{
Jonathas Xavier Pereira' \\ Yuri Cavalcante ${ }^{2}$ \\ Riane Wanzeler de Oliveira ${ }^{3}$ \\ 'Department of Pathology, Faculty \\ of Medicine, ${ }^{2}$ Faculty of Dentistry, \\ ${ }^{3}$ Faculty of Medicine, Federal \\ University of Rio de Janeiro, Rio de \\ Janeiro, Brazil
}

This article was published in the following Dove Press journal:

Clinical, Cosmetic and Investigational Dermatology

23 February 2017

Number of times this article has been viewed
Background: The adipocytolytic non-surgical esthetic procedures are indicated for the reduction of localized fat and are effective in reducing local adiposity through the ablation of adipocytes with fast and lasting results, besides causing local inflammation.

Objective: This study aimed to characterize the adipocytolytic procedures and correlate the phases of the inflammatory process with the results obtained from such procedures, in order to clarify the role of inflammation triggered by the adipocytolytic procedures and its relation with the lipolytic process, with a focus on body shaping.

Methods: This work is an integrative literature review that presents a total of 72 articles published between 1998 and 2015, derived from the PubMed database, in order to establish a relationship between clinical and basic science research, assuming an important role in medical practice based on evidence.

Results: The results show that the adipocytolytic procedures are characterized by triggering inflammation arising from the disruption of adipocytes by interfering with the lipolytic signaling pathways in both acute and chronic phases of inflammation through the direct action of proinflammatory cytokines or catecholamines. Therefore, inflammation plays an important role in modulating the lipolytic process, influencing body shaping.

Conclusion: The inflammatory process assists the adipolytic process in all stages of inflammation, contributing to the reduction of body contouring.

Keywords: inflammation, body contouring, esthetic procedures, adipocytolysis

\section{Introduction}

Overweight is a body alteration that is independent of lean body mass; however, it is directly related to the adipose tissue. Overweight is a nonpathologic condition, although evolution can lead to obesity (body mass index $\geq 30 \mathrm{~kg} / \mathrm{m}^{2}$ ), which increases the development of several chronic inflammatory diseases. ${ }^{1-4}$

Fat tissue is derived from a mesenchymal precursor and this differentiation may follow two routes to generate either unilocular fat tissue (white) or multilocular (brown). The maturation of these cells is dependent on the receptor activated by peroxisome proliferator- $\gamma$ and the transcription factor CEBP- $\alpha$. The white fat tissue has the function of energy reserves and endocrine secretion. The location may be visceral or subcutaneous, which is related to the localized fat. ${ }^{2,5-8}$ The lipid accumulation in adipocytes is controlled by insulin and prostaglandins; on the other hand, the breakdown and release of these lipids are regulated by noradrenaline, glucagon, adrenocorticotropic hormone and steroid hormones. ${ }^{2,6,9,10}$
Correspondence: Jonathas Xavier Pereir Faculty of Medicine, Department of Pathology, Federal University of Rio de Janeiro, Av. Carlos Chagas Filho, 393 Bloco F, CEP 21941-902, Cidade Universitária, Ilha do Fundão, Rio de Janeiro, Brazil

Tel +5502139386483

Email jonathasxp@gmail.com 
Recent research has shown that adipose tissue is able to release cytokines, chemokines and adipokines, which participate in autocrine or paracrine signaling pathways, with effects in the adipose tissue as in other surrounding tissues (endocrine activity). These cytokines have many functions, among which we can mention immune modulation and even modulating the lipolytic process, in other words, mobilization of fat from the adipocytes. The chemokineproducing cells are adipocytes, preadipocytes and macrophages especially. ${ }^{9,11}$

The heterogeneous locations of the unilocular white adipose tissue when associated with overweight culminates in an esthetic disorder called localized fat or focal adiposity, which is currently rejected by the populations based on their cultural values. ${ }^{1-3}$ The increasing demand by the populations worldwide for body fat reduction methods stimulates the development of safer and more effective techniques and approaches in the field of esthetic medicine, with regard to surgical and nonsurgical medical interventions. ${ }^{1,12-14}$

The most commonly used medical approaches for weight loss, aimed at reducing the subcutaneous adipose tissue, are surgical (lipectomy), such as liposuction and abdominoplasty, among other procedures. However, the growing desire for weight loss among the people encouraged the emergence and improvement of techniques for nonsurgical body contouring, among which can be mentioned cryolipolisis, radiofrequency, phototherapy (laser and light), injectable lipolytic (mesotherapy), hydrolipoclasy, low-intensity focused ultrasound, high-intensity focused ultrasound, cavitation and others therapies. These techniques have the following advantages: they are usually painless, although it is a subjective aspect, lead to quick recovery, require little or no downtime, have few adverse effects and are safer. However, the surgical approaches for body contouring have increased the risk of death, infection, embolism, visceral perforation, seroma, nerve compression, swelling, anesthetic toxicity, scars and surface irregularities, besides having high costs. ${ }^{12,13,15-20}$ Generally, diversified nonsurgical techniques suitable for the reduction of localized fat and applied in clinical practice have lipolytic action aimed at reducing the local adiposity. ${ }^{21}$

Lipolysis is the term given to the hydrolysis of lipids into their respective metabolites: fatty acids and glycerol. This process occurs in the adipocyte and is physiologically controlled by the enzymatic action of the hormone-sensitive lipase (HSL) and lipoprotein lipase. The HSL is intracellularly expressed in adipocytes, and its activation is dependent on catecholamines, natriuretic peptides, growth hormones, glucocorticoids and tumor necrosis factor- $\alpha$ (TNF- $\alpha)$ and inhibition is dependent on insulin. The lipoprotein lipase is synthesized in the adipocytes and transferred to the endothelial cells of blood capillaries (extracellular), and is responsible for the chylomicron breaks arising from food and very-low density lipoproteins. ${ }^{6,21,22}$

The hypertrophy caused by increased lipid inclusion in the adipose tissue results in several metabolic consequences for the adipocytes. The physiologic lipolytic process induces other processes such as innate immune response activation and the activation of resident macrophages in the adipose tissue. Importantly, in the context of physiologic lipolysis, no inflammatory process is involved in the clearance of fatty acids, since these are unsaturated and do not trigger proinflammatory signaling pathways. . $^{11,23,24}$

On the other hand, saturated lipids are able to activate the endotoxin inflammatory pathway through the toll-like 4 receptor (TLR4) present in resident macrophages of the adipose tissue. The lipid clearance stimulates chemotaxis of monocytes arising from hematopoietic bone marrow in a directly proportional manner, through the production and release of monocyte chemoattractant protein 1 chemokine by the adipocytes and its effect on the chemokine receptor present in macrophages and monocytes. These monocytes differentiate into macrophages when infiltrating the adipose tissue and are activated by saturated fatty acids, firing endotoxin pathway. The endotoxin pathway culminates in the activity of the nuclear transcription factor NF- $\kappa \beta$ responsible for transcribing proinflammatory genes that induce the production and release of TNF- $\alpha$ by the macrophages and is also able to stimulate the adipocytes to produce and release proinflammatory adipokines. Thereby, a vicious circle between the activation of macrophages and production of adipokines from the adipocytes is generated..$^{11,23-26}$

Lipolysis is a physiologic process regulated by multiple signaling pathways and is the basis for the nonsurgical methods for the reduction of localized fat. These methods can be classified into noncytolytic methods and cytolytic methods (adipocytolysis). ${ }^{22,27}$

Noncytolytic methods are techniques to stimulate the mobilization of lipids by the adipocytes without affecting their functions or the integrity of their cell membranes. These techniques act as temporary metabolic enhancers, encouraging the breakdown of lipids into fatty acids and glycerol to be mobilized out of the adipocyte and their subsequent metabolism by the liver. The disadvantages of these methods are that their effects in the adipose tissue and body shaping tend to be transient. Such methods are associated with physiologic lipolytic signaling pathways. ${ }^{21,27,28}$ 
The cytolytic methods, also known as adipocytolysis, are techniques to break or solubilize lipids through the partial or total ablation of adipocytes, destroying their plasma membrane. These techniques promote chemical or mechanical ablation, causing permanent changes in the adipocytes and promoting improvement in the body contouring and reduction in the body fat with extended long-term effect. ${ }^{21,27}$

Among the nonsurgical procedures that use adipocytolytic principles, we can highlight high-intensity focused ultrasound, ultrasound cavitation, radiofrequency ablation, ablative laser and mesotherapy (sodium deoxycholate). The cellular changes caused by such techniques on the adipocyte membrane are: rupture of the membrane by cavitation, thermal damage, poration of the membrane, lysis and membrane emulsification. All adipocytolytic procedures trigger local inflammation evidenced by the appearance of local adverse effects arising from permanent alterations caused in the adipose tissue. ${ }^{12,15,17,19,21,27,29-37}$

This study aims to characterize the adipocytolytic procedures and relate the phases of the inflammatory process with the results obtained from such procedures, in order to clarify the role of inflammation and its influence on the lipolytic process. This integrative literature review confronts the clinical data related to adipocytolytic esthetic procedures with basic science research data related to inflammation in the adipose tissue and its local effects, assuming an important role in medical practice based on evidence, in order to improve the understanding of adipocytolytic esthetic procedures and their effects on body contouring.

\section{Methods}

This study is an integrative literature review based on the model proposed by Whittemore and Knafl. ${ }^{38}$ The selection of articles gave a total of 72 studies published between 1998 and 2015, derived from the PubMed database, which were divided into two groups: clinical research studies (41 articles) and basic sciences studies ( 31 articles). Of the total studies, 53 are original scientific articles and 19 are literature reviews, as shown in Figure 1.

The classification of articles in the two groups was performed according to the methodology adopted for each study. If the article used clinical data as a research resource, the classification was "clinical research studies". If the article used experimental data as a research resource, the classification was "basic science studies".

The selection of the clinical research studies group was based on the following inclusion criteria: articles containing the search keywords "human body contouring" or "human body sculpting" or "human fat reduction" or "human adipocytolytic". However, the articles that contain only surgical and/ or nonadipocytolytic techniques, according to Rotunda ${ }^{21}$ and Mulholland and Kreindel, ${ }^{27}$ were excluded. This methodology aimed at selecting the articles strictly related to clinical data with a focus on noninvasive and noncytolytic human body contouring.

The selection of the basic sciences studies group was based on the following inclusion criteria: articles containing the search keywords "inflammation and adipose tissue" or "adipocyte cytolysis" or "adipose tissue reduction". However, the articles that do not relate to white adipose tissue and human model were excluded. This methodology aimed at selecting of articles strictly related to basic science data, with the focus on inflammation and damage in adipose tissue.

After the classification and selection of articles, the clinical research group was confronted with the basic research group, aiming to improve the understanding of adipocytolytic esthetic procedures and their effects on body contouring.

\section{Results \\ Database analysis}

The selected articles were counted and grouped into a contingency table, in which was analyzed the relationship between the nature of research, basic or clinical, and the type of publication, review articles or original articles. Fisher's test for statistical analysis of contingency was performed, presenting a $p$ value of 0.5706 . This indicates there was no significant difference between the article groups, showing a homogeneous distribution of the articles in the testing groups, minimizing possible selection bias, as shown in Figure 1.

\section{Characterization of adipocytolytic procedures}

The adipocytolytic esthetic procedures were characterized by Rotunda ${ }^{21}$ and Salti et $\mathrm{al}^{39}$ as techniques to break the adipocyte membrane, releasing its cytoplasmic contents into the interstitial tissue. These techniques, according to Mulholland and $\mathrm{Kreinde}^{27}$ and Thuangtong et al, ${ }^{37}$ cause tissue changes and permanent injuries to the fat cells. These effects are achieved through cavitation, thermal damage, formation of pores in the plasma membrane and solubilization of plasma membrane. ${ }^{19,21,27,29,37,39}$ Figure 2 illustrates the differences between the noncytolytic mechanisms (Figure 2A) and the adipocytolytic mechanisms (Figure 2B).

Cryolipolysis is a technique that can reduce body measurements. Although its inflammatory mechanism is not completely understood, the basic science literature reports 


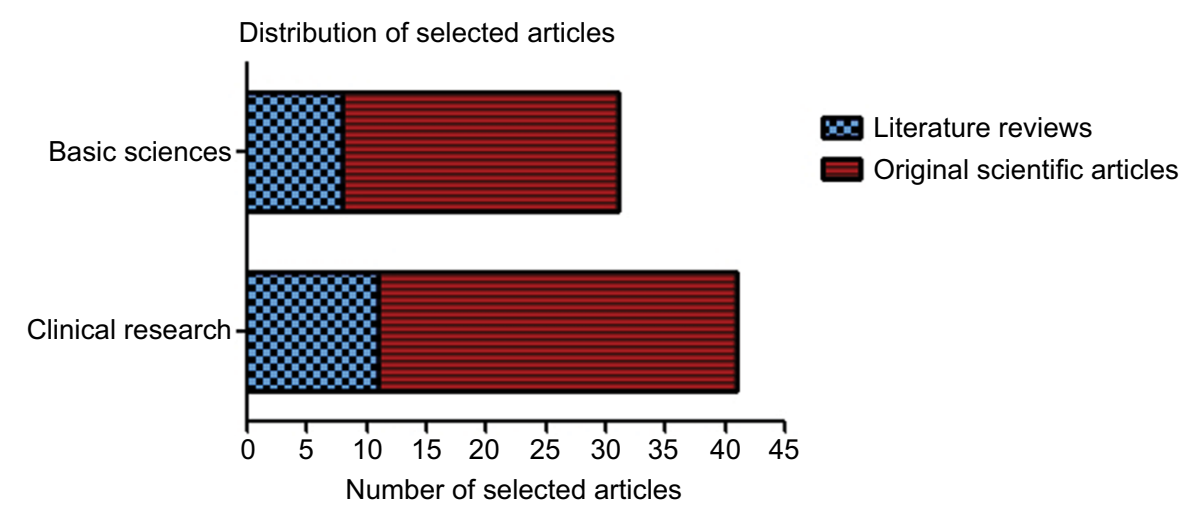

Figure I Distribution of selected articles.

Notes: A total of 72 articles were counted and grouped into a contingency table, where we analyzed the relationship between the nature of research, basic or clinic, and the type of publication, review articles or original articles. We used Fisher's test for statistical analysis of contingency ( $p=0.5706)$ by GraphPad Prism software, version 5.0 (GraphPad Software, Inc., La Jolla, CA, USA).

A

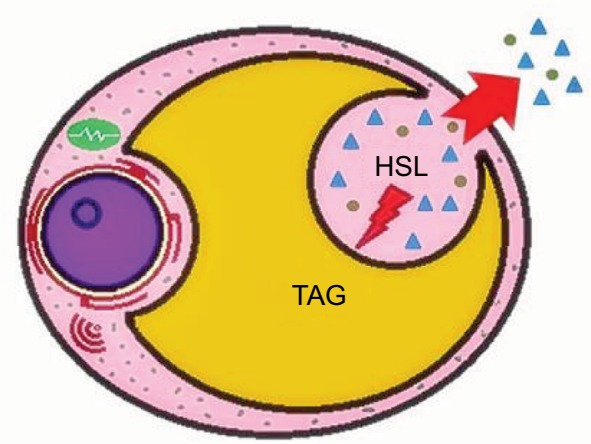

Fatty acid

Glycerol

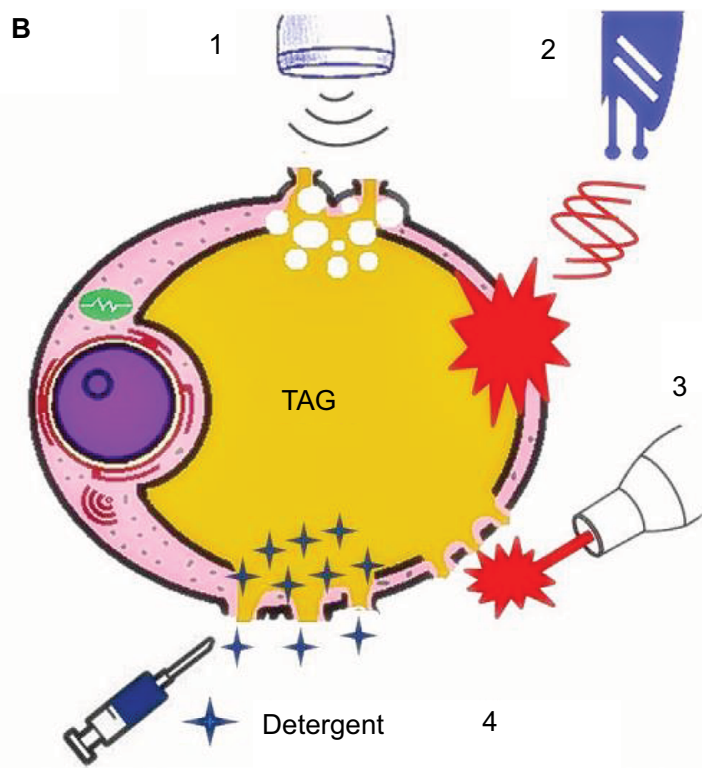

Figure 2 Noncytolytic mechanism and adipocytolytic mechanisms.

Notes: (A) An illustrated noncytolytic mechanism (physiologic lipolysis), where the triacylglycerol (TAG) is broken down into fatty acids and glycerol by hormone-sensitive lipase (HSL) and these leave the adipocyte by simple diffusion without changing the cell membrane. (B) The cytolytic mechanisms are illustrated: (I) cavitation by highintensity ultrasound; (2) thermal damage through ablative radiofrequency; (3) formation of pores in the membrane through laser diode; and (4) membrane solubilization and emulsification through mesotherapy with detergent (sodium deoxycholate).

apoptotic cell death, in contrast to the clinical data that report the presence of an intense inflammatory process. Although cryolipolysis is an adipocytolytic procedure, there is no consensus in the scientific literature about the membrane disruption mechanism, as described by Rotunda..$^{21,40-44}$

\section{Cellular changes and possible adverse effects}

Cellular changes in the adipose tissue, caused by adipocytolytic procedures, culminate in tissue damage due to cell death process undergone by adipocytes, which can be promoted by necrosis. ${ }^{45,46}$ In Table 1 are outlined the most widely used techniques for body sculpting through adipocytolytic procedures and their mechanisms, cellular changes and possible local adverse effects.

Analysis of Table 1 indicates that all possible local adverse effects derived from adipocytolytic procedures stem from the inflammatory reactions of acute and chronic nature, triggered by changes exerted on the plasma membrane of adipocytes, generating an immune response mediated by chemotactic inflammatory cells in septa and areas of subcutaneous fat lobules. . $^{35,36,47,48}$

\section{Inflammation derived from adipocytolysis}

Disruption of the cell plasma membrane in response to physical or chemical aggression derived from esthetics procedures, 
Table I Adipocytolytic procedures

\begin{tabular}{|c|c|c|c|c|}
\hline $\begin{array}{l}\text { Adipocytolytic } \\
\text { procedures }\end{array}$ & Mechanisms & Cellular changes & Possible adverse effects & References \\
\hline HIFU & $\begin{array}{l}\text { Cavitation and thermal } \\
\text { disruption }\end{array}$ & $\begin{array}{l}\text { Disruption of plasma } \\
\text { membrane }\end{array}$ & $\begin{array}{l}\text { Pain, bruise, edema, } \\
\text { dysesthesia and erythema }\end{array}$ & $I, 14,17,18,30,31,33,47,66-69$ \\
\hline $\begin{array}{l}\text { No thermal cavitation } \\
\text { ultrasound }\end{array}$ & Cavitation & $\begin{array}{l}\text { Disruption of plasma } \\
\text { membrane }\end{array}$ & Mild pain & $15,18,19,46,72$ \\
\hline Radiofrequency ablation & Thermal damage & $\begin{array}{l}\text { Damage to the plasma } \\
\text { membrane }\end{array}$ & $\begin{array}{l}\text { Transient erythema and } \\
\text { little pain }\end{array}$ & $I, 12,14,17,27,32$ \\
\hline Laser ablation & Poration & $\begin{array}{l}\text { Formation of pores in the } \\
\text { membrane }\end{array}$ & $\begin{array}{l}\text { Rare swelling or local } \\
\text { erythema }\end{array}$ & $\mathrm{I}, 14,18,34,73$ \\
\hline $\begin{array}{l}\text { Mesotherapy (sodium } \\
\text { deoxycholate) }\end{array}$ & $\begin{array}{l}\text { Solubilization and } \\
\text { emulsification }\end{array}$ & $\begin{array}{l}\text { Disruption of plasma } \\
\text { membrane and } \\
\text { emulsification }\end{array}$ & $\begin{array}{l}\text { Pain, bruise, urticaria, } \\
\text { panniculitis }\end{array}$ & $21,18,20,29,35-37,39,48,74-77$ \\
\hline
\end{tabular}

Abbreviation: HIFU, high-intensity focused ultrasound.

leading to cell death by primary necrosis, results in the display and release of intracellular molecules not found physiologically in the extracellular environment. Such endogenous molecules are known as damage-associated molecular patterns (DAMPs) and are capable of activating TLR, advanced glycation end products receptor and ST2 receptors. In the specific case of adipocytes, saturated fatty acids present in their lipid content also act as DAMP, activating the endotoxin pathway through recognition by TLR4+ phagocytes such as macrophages residents of adipose tissue. ${ }^{11,23,24,26,46}$

Saturated fatty acids released by adipocytolysis induce macrophage activation, leading to the production and liberation of proinflammatory cytokines, such as TNF- $\alpha$, which is also produced in the adipocytes and, hence, released by their disruption. This interaction occurring between lysed fat cells and macrophage activation is negatively regulated by the suspension of adipocytolytic stimulation, neutralization of DAMPs, anti-inflammatory cytokines produced and released by the adipose tissue, physical exercises, activating transcription factor 3 activation in the macrophages, downregulation of the $M A F B$ gene and vitamin E. $4,8,24-26,30,49,50$

The macrophages, once activated by the presence of DAMPs and recruited by the release of proinflammatory cytokines originating from adipocytolysis, acquire proinflammatory phenotype characterized by macrophage polarization 1 (M1) and produce TNF- $\alpha$, interleukin (IL)-6, nitric oxide, among others proinflammatory molecules. In turn, the release of proinflammatory cytokines originating from the damaged fatty tissue, combined with the release of proinflammatory cytokines derived from activated M1 macrophages results in the local induction of resistance to insulin, lipolysis stimulation and inhibition of adipogenesis, as previously shown by Grant and Stephens. ${ }^{22}$ In Figure 3 is illustrated the mechanism of macrophage activation phenotype M1, triggered by adipocytolysis and release of proinflammatory cytokines by both adipocytes lysates, intact adipocytes and also by activated macrophages. ${ }^{4,11,22,26,46}$

Adipose tissue macrophages have great significance in the initiation and regulation of the inflammatory process, since their polarization triggers dichotomous effects. The proinflammatory M1 polarization, also called the classical activation of macrophages, is responsible for mediating TH1-type immune responses, with insulin resistance effects, lipolysis stimulation and inhibition of adipogenesis in the adipose tissue. On the other hand, anti-inflammatory M2 polarization, also called alternative macrophage activation, is the polarization most commonly found in expanding adipose tissue, which is being

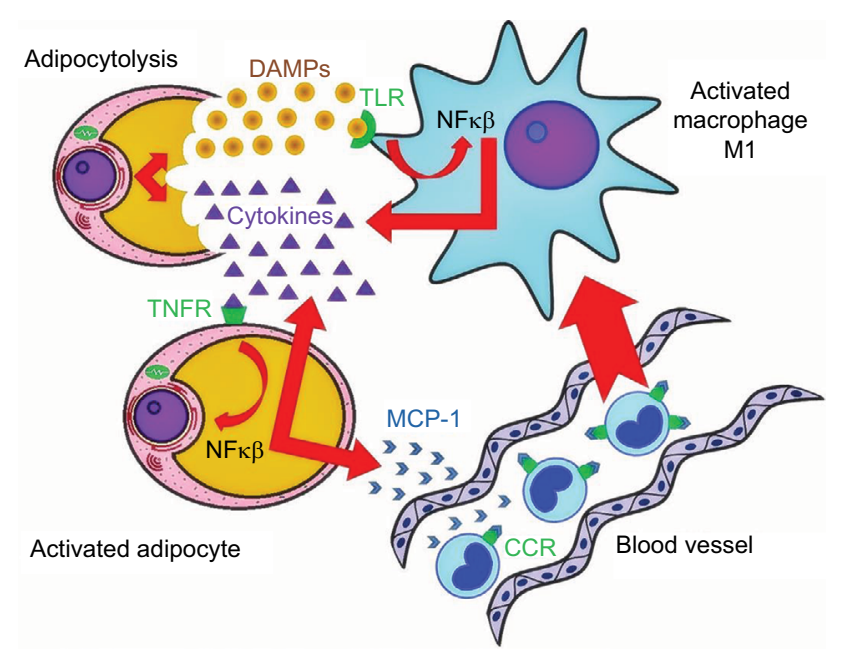

Figure 3 Adipocytolysis and MI macrophages.

Notes: The figure shows adipocytolysis releasing cytokines and damage-associated molecular patterns (DAMPs), which activate toll-like receptors (TLRs) on the macrophages, which, in turn, produce and release proinflammatory cytokines by the activity of nuclear factor $\kappa \beta$ (NFK $\beta$ ). These cytokines released by both the macrophages and adipocytolysis are capable of activating intact adipocytes and are also capable of producing more proinflammatory cytokines and monocytes chemotactic protein I (MCP-I) by activation of the tumor necrosis factor receptor (TNFR) with consequent NFא $\beta$ activation. MCP-I attracts the monocytes through the activation of chemokine receptor (CCR), promoting the infiltration of monocytes into the tissue and their differentiation into macrophages, which upon contact with the high content of proinflammatory cytokines arising from the adipocytolysis acquire the MI proinflammatory polarity.

Abbreviation: MI, macrophage polarization I. 
responsible for mediating TH2-type immune responses by exerting direct effects on glucose uptake in the adipocytes by insulin pathway, lipolysis inhibition and lipogenesis activation. In adipocytolysis, M1 macrophages are concentrated around the necrotic cells due to the local gradient of proinflammatory cytokines, while M2 macrophages are randomly dispersed by the adipose tissue. . $^{49,51-54}$

The above data suggest that acute inflammation arising from adipocytolytic procedures is directly related to the appearance of local adverse effects and acts by helping the lipolytic process objectified by the procedures of body sculpting. The adipocytolysis reduces the number of adipocytes in the subcutaneous adipose tissue due to lysis of membranes and consequent cell death by necrosis. It also stimulates lipolysis by reducing the local accumulation of lipids in intact neighboring adipocytes, since the proinflammatory cytokines of the adipocytolytic microenvironment act locally, thereby contributing to the reduction of localized subcutaneous adipose tissue and reduction of body measurements.

The local inflammatory consequences derived from the adipocytolytic process are: triacylglycerol accumulation in macrophages, formation of foam cells or giant cells, granulomatous panniculitis and high lipid efflux derived from adipose tissue with consequent drainage through the lymphatic system. ${ }^{23,31,35}$ In contrast, systemic effects of inflammation derived from adipocytolytic process are demonstrated in experimental models, ${ }^{36}$ such as alterations in liver enzymes with increased esterase choline activity, reduction in alanine aminotransferase and aspartate aminotransferase activities and changes in lipid profile with increased rate of serum triacylglycerol and free fatty acids. There is no evidence in the literature that identifies systemic changes in the inflammatory profile of the post-procedure blood. ${ }^{36}$

\section{Repair tissue derived from adipocytolysis}

Once the acute inflammatory stimulus is completed, the TH1 type immune response clears the acute inflammatory process. M1 macrophages reduce the production of proinflammatory cytokines and begin to produce anti-inflammatory cytokines, returning to macrophage configuration commonly observed in individuals with growing adipose tissue: the M2 polarization. ${ }^{8,24-26,30,49-52}$

The M2 macrophage polarization, also called alternative activation, is responsible for immunomodulation and tissue repair. It is characterized by the production of anti-inflammatory cytokines such as IL-10 and IL-1 and growth factors such as platelet-derived growth factor, transforming growth factor- $\beta$, basic fibroblast growth factor and vascular endothelial growth factor. M2 macrophages also produce arginase, an enzyme that inhibits the production of free radicals which are present in the polarization M1. This anti-inflammatory effect is achieved by modulating TNF- $\alpha$, generating an increase in blood levels of IL-10 coupled to increased insulin sensitivity by the adipose tissue observed in humans. ${ }^{22,51,53,55,56}$

M2 macrophages activate the acquired immune response $\mathrm{TH} 2$, presenting antigens and inducing the production of specific antibodies to complete the clearance of the remaining products of acute inflammation. The production and release of growth factors such as fibroblastic growth factor, for example, will stimulate the synthesis of extracellular matrix by the fibroblasts and also stimulate local angiogenesis by other factors. M2 polarization is induced by IL-4 and IL-13 in macrophages and their pathways culminate in the STAT6 transcription factor activation responsible for the production of catecholamines such as adrenaline and noradrenaline. These catecholamines, in turn, act on intact adipocytes through $\beta 3$ adrenergic receptors, inducing phosphorylation of perilipins and activation of HSL, culminating in the physiologic lipolytic effect. According to Grant and Stephens ${ }^{22}$ and Nguyen et al, ${ }^{58}$ the lipolytic effects are also obtained by an alternative activation of macrophages (M2 polarization) through the release of these catecholamines induced by anti-inflammatory cytokines, constituting an indirect lipolytic effect, since the cytokines do not act directly on the adipocytes to induce lipolysis. In Figure 4 is illustrated the mechanism of M2 macrophage activation in the context of adipocytolysis and the release of growth factors and catecholamines by the macrophages. ${ }^{22,55-59}$

The growth factors produced by M2 macrophages have local effects characterized by the appearance of a new stromal granular structure, rich in capillaries, resulting from intense angiogenic and fibroblastic stimulation in the adipocytolytic site. This new stroma is called granulation tissue, the main function of which is to serve as a structural basis for the internal cell growth in the adipocytolytic site, in addition to providing blood supply. Fibroblasts deposit fibrin, fibronectin and hyaluronic acid in the adipocytolytic site for the connective granulation tissue formation, which is transitory and subsequently replaced by collagen matrix due to the transforming growth factor- $\beta 1$ produced and secreted by the M2 macrophages acting on fibroblasts. ${ }^{53,56,57}$

Approximately 1 week after adipocytolytic stimulation, fibroblasts assume the myofibroblast phenotype, presenting actin microfilaments in their cytoplasm and performing a contractile function. This function is essential to the contraction of the affected area and deposition of the collagen 


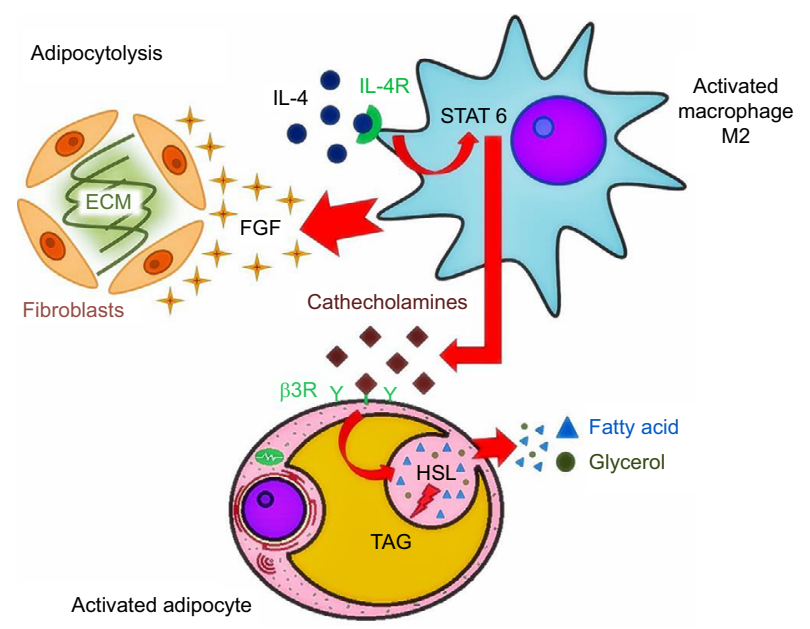

Figure 4 Adipocytolysis and M2 macrophages.

Notes: The figure shows the activation of macrophages in the macrophage polarization 2 (M2) polarization through interleukin (IL) 4 interacting with the IL-4R, activating transcription factor STAT6, culminating with the release of catecholamines capable of acting on $\beta 3$ adrenergic receptors $(\beta 3 R)$ present in neighboring adipocytes. Once the adrenergic pathway is activated, the adipocytes begin the physiologic lipolytic process due to activation of hormone sensitive lipase (HSL) which operates in the breakdown of triacylglycerol (TAG) into fatty acids and glycerol. Besides producing catecholamines, M2 macrophages also produce growth factors such as fibroblastic growth factor (FGF), responsible for the proliferation of fibroblasts, which in turn produce extracellular matrix (ECM) and deposit collagen on the adipocytolytic site.

matrix. The replacement of granulation tissue by deposition of collagen matrix depends mainly on the action of metalloproteinases and culminates in the tissue repair process characterized by the presence of fibroblasts, responsible for the production of collagen matrix local deposition. Thus, the healing process promotes local retraction of the tissue

\section{A}

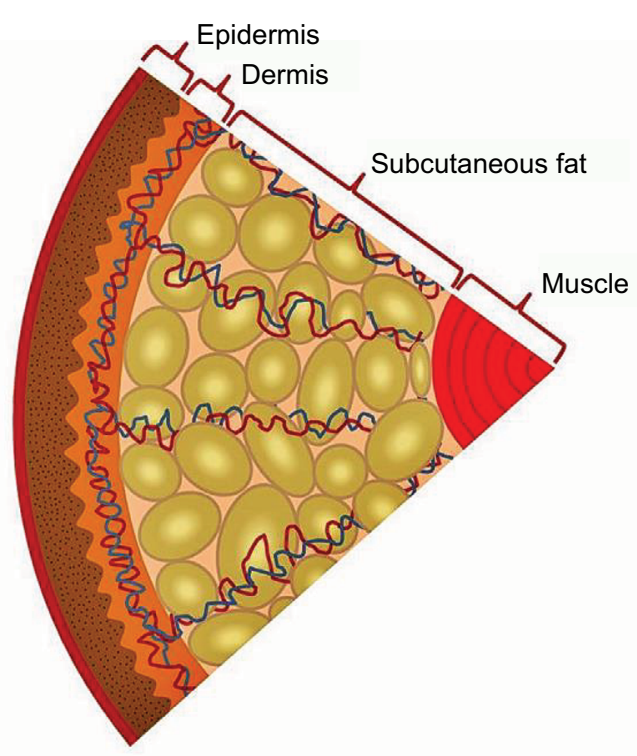

not only by myofibroblasts' participation, but also by the collagen type I and III deposition as a result of tissue repair process, in contrast to collagen type VI normally found in the fatty tissue. ${ }^{49,56,57,60,61}$

The scarring collagen (type I and III) deposited in the adipocytolytic site forms fibers bonded intermolecularly by crosslinking that are more cohesive and resistant compared to fibers commonly found in adipose tissue (collagen VI). This fact contributes to the fibrotic process that, in turn, prevents cell proliferation and cell migration to the adipocytolytic area by steric hindrance, featuring a cohesive and acellular scar, able to promote the retraction of the area, helping in the process of body contouring and avoiding sagging skin, commonly observed in nonadipocytolytic weight loss process. Figure 5 illustrates the fibrotic process (tissue repair) in the adipocytolytic site and its contribution to the reduction of body contouring. ${ }^{49,57,60,62}$

\section{Consequences of adipocytolytic procedures}

The adipocytolytic procedures may culminate in fibrosis which is derived from the tissue repair process, but can also lead to remodeling through the metalloproteinases activity and tissue regeneration process as a result of mesenchymal stem cell activity from the adipose tissue. ${ }^{60,61}$

In regenerative case, the collagen deposited on the adipocytolytic environment is replaced by new adipocytes which will colonize the area, regenerating and generating

B

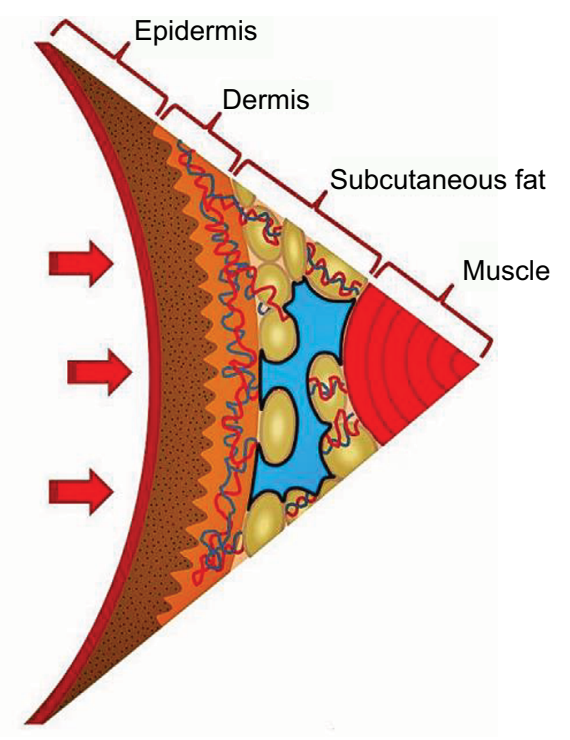

Figure 5 Adipocytolysis and tissue repair.

Notes: Illustration of epidermis, dermis and subcutaneous tissue under physiologic conditions (A) and adipocytolytic context (B), where collagen deposition (light blue area), the smallest number of adipocytes and predominance of smaller adipocytes compared to normal structure are observed. The red arrows indicate the retraction of epidermis and dermis due to reduction in subcutaneous fat layer, culminating with the deposition of collagen I and III, retracting the adipocytolytic area, contributing to the reduction of body measures and skin sagging. 
hyperplasia of adipose tissue. In case of persistence of fibrosis, there are clinical reports demonstrating that the adipose tissue is capable of undergoing compensatory hypertrophy. Due to these factors, after adipocytolytic procedures, lipid deposition should be avoided by physical exercise and proper diet to ensure body sculpting, contributing to the continued loss of body measurements. .,62-64 $^{4}$

Involvement of the immune response in the resolution of the adipocytolytic process added to the changes in liver enzymes and lipid profile with increased synthesis of serum triacylglycerol and free fatty acids to systemic levels. This highlights the importance of carrying out laboratory tests with hematologic analyses and lipidic, immunologic, liver and kidney profile before performing any adipocytolytic procedure, thereby avoiding post-procedure complications..$^{20,21,36,46,49,65-77}$

\section{Discussion}

This study aimed to characterize the adipocytolytic procedures, corroborating the classification suggested by Rotunda ${ }^{21}$ and Mulholland and Kreindel. ${ }^{27}$ These procedures demonstrate inflammatory reactions triggered by adipocytolysis. These inflammatory reactions are well discussed in the clinical literature, but little explored in the basic or experimental science literature.

The confrontation between the clinical data, related to adipocytolytic esthetic procedures, with basic science research data, related to inflammation in adipose tissue and its local effects, supports the hypothesis that the inflammatory process assists the adipocytolytic process in all stages of inflammation, either directly by the action of proinflammatory cytokines or indirectly through the release of catecholamines.

The scarcity of research in the scientific literature, relating the molecular basis of inflammation observed in esthetic procedures to their adverse effects and outcomes, affects the understanding of the mechanism of action of adipocytolytic techniques applied to esthetic medicine.

Although the scientific literature is generally favorable to this therapeutic approach for the treatment of localized fat, more clinical or experimental research is needed to validate the effective participation of inflammatory pathways in the lipolytic process triggered by adipocytolytic esthetic procedures.

Although this study is the first review to confront clinical and basic research about the adipocytolytic procedures, it is not possible to propose a mechanism of action to explain the influence of inflammation in adipocytolytic process. However, the present integrative review plays an important role in medical practice based on evidence, to improve the understanding of adipocytolytic esthetic procedures and their effects on body sculpture.

\section{Conclusion}

The inflammatory process generated by nonsurgical adipocytolytic procedures can improve the efficacy of these procedures by stimulating the lipolytic process. According to scientific literature, the inflammatory process assists the adipocytolytic process in all stages of inflammation, either directly by the action of proinflammatory cytokines or indirectly through the release of catecholamines.

Deposition of scarring collagen from the tissue repair presents more cohesive and resistant collagen fibers, preventing cell proliferation and cell migration to the adipocytolytic area by being capable of promoting the shrinkage of the area, helping the reduction process of body contouring and avoiding sagging skin commonly observed in rapid weight loss process.

The inflammatory process triggered by adipocytolytic procedures may result in tissue regeneration or fibrosis. In both cases, the deposit of lipids should be avoided through the practice of appropriate physical exercise and proper diet in order to avoid compensatory hyperplasia or hypertrophy of adipose tissue and to maintain the obtained results.

\section{Disclosure}

The authors report no conflicts of interest in this work.

\section{References}

1. Kennedy J, Verne S, Griffith R, Falto-Aizpurua L, Nouri K. Non-invasive subcutaneous fat reduction: a review. JEADV. 2015;29(9):1679-1688.

2. Saber M, Shalaby S, Kharbotly A, Taher N, Saber LM, Medhat A. Effect of ultrasound cavitation therapy as a non-invasive approach on adipose tissue thickness in Egyptian women. J Appl Sci Res. 2013; 9(11):5964-5969.

3. Friedmann DP, Avram MM, Cohen SR, et al. An evaluation of the patient population for aesthetic treatments targeting abdominal subcutaneous adipose tissue. J Cosmet Dermatol. 2014;13(2):119-124.

4. Kawanishi N, Yano H, Yokogawa Y, Suzuki K. Exercise training inhibits inflammation in adipose tissue via both suppression of macrophage infiltration and acceleration of phenotypic switching from $\mathrm{m} 1$ to $\mathrm{m} 2$ macrophages in high-fat-diet-induced obese mice. Exerc Immunol Rev. 2010;16:105-118.

5. Shen W, Wang Z, Punyanita M, et al. Adipose tissue quantification by imaging methods: a proposed classification. Obes Res. 2003;11(1):5-16.

6. Greco EA, Lenzi A, Migliaccio S. The obesity of bone. Ther Adv Endocrinol Metab. 2015;6(6):273-286.

7. Coelho M, Oliveira T, Fernandes R. Biochemistry of adipose tissue: an endocrine organ. Arch Med Sci. 2013;9(2):191-200.

8. Queiroz JCF, Alonso-Vale MIC, Curi R, Lima FB. [Control of adipogenesis by fatty acids]. Arq Bras Endocrinol Metab. 2009;53(5):582-594. Portuguese.

9. Knudsen JG, Bertholdt L, Joensen E, Lassen SB, Hidalgo J, Pilegaard H. Skeletal muscle interleukin-6 regulates metabolic factors in iWat during HFD and exercise training. Obesity. 2015;23(8):1616-1624. 
10. Alves JG, Falcão RW, Pinto RA, Correia JB. Obesity patterns among women in a slum area in Brazil. J Health Popul Nutr. 2011;29(3): 286-289.

11. Coppack SW. Pro-inflammatory cytokines and adipose tissue. Proc Nutr Soc. 2001;60(3):349-356.

12. Adatto MA, Adatto-Neilson RM, Morren G. Reduction in adipose tissue volume using a new high-power radiofrequency technology combined with infrared light and mechanical manipulation for body contouring. Lasers Med Sci. 2014;29(5):1627-1631.

13. Kinney BM. Body contouring with external ultrasound. safety and efficacy report. Plast Reconstr Surg. 1999;103(2):728-729.

14. Reddy BY, Hantash BM. Emerging technologies in aesthetic medicine. Dermatol Clin. 2009,27:521-527.

15. Godoy FB, Fonseca BB, Levenhagen MA, Franco MA, Melo RT, Beletti ME. Structural changes of fat tissue after nonaspirative ultrasonic hydrolipoclasy. J Cutan Aesthet Surg. 2011;4(2):105-110.

16. Jastrzębska-Mierzyńska M, Ostrowska L, Hady HR, Dadan J, Konarzewska-Duchnowska E. The impact of bariatric surgery on nutritional status of patients. Wideochir Inne Tech Maloinwazyjne. 2015;10(1):115-124.

17. Mulholland RS, Paul MD, Chalfoun C. Noninvasive body contouring with radiofrequency, ultrasound, cryolipolysis and low-level laser therapy. Clin Plastic Surg. 2011;38(3):503-520.

18. Jewell ML, Solish NJ, Desilets CS. Noninvasive body sculpting technologies with an emphasis on high-intensity focused ultrasound. Aesth Plast Surg. 2011;35(5):901-912.

19. Brown S, Greenbaum L, Shtukmaster S, Zadok Y, Ben-Ezra S, Kushkuley L. Characterization of nonthermal focused ultrasound for noninvasive selective fat cell disruption (lysis): technical and preclinical assessment. Plast Reconstr Surg. 2009;124(1):92-101.

20. Herreros FO, Moraes AM, Velho PE. Mesotherapy: a bibliographical review. An Bras Dermatol. 2011;86(1):96-101.

21. Rotunda AM. Injectable treatments for adipose tissue: terminology, mechanism and tissue interaction. Lasers Surg Med. 2009;41(10):714-720.

22. Grant RW, Stephens JM. Fat in flames: influence of cytokines and pattern recognition receptors on adipocyte lipolysis. Am J Physiol Endocrinol Metab. 2015;309(3):E205-E213.

23. Kosteli A, Sugaru E, Haemmerle G, et al. Weight loss and lipolysis promote a dynamic immune response in murine adipose tissue. J Clin Invest. 2010;120(10):3466-3479.

24. Caspar-Bauguil S, Kolditz CI, Lefort C, et al. Fatty acids from fat cell lipolysis do not activate an inflammatory response but are stored as triacylglycerols in adipose tissue macrophages. Diabetologia. 2015;58(11):2627-2636.

25. Heilbronn LK, Campbell LV. Adipose tissue macrophages, low grade inflammation and insulin resistance in human obesity. Curr Pharm Des. 2008;14(12):1225-1230.

26. Suganami T, Yuan X, Shimoda Y, et al. Activating transcription factor 3 constitutes a negative feedback mechanism that attenuates saturated fatty acid/toll-like receptor 4 signaling and macrophage activation in obese adipose tissue. Circ Res. 2009;105(1):25-32.

27. Mulholland RS, Kreindel M. Non-surgical body contouring: introduction of a new non-invasive device for long-term localized fat reduction and cellulite improvement using controlled, suction coupled, radiofrequency heating and high voltage ultra-short electrical pulses. J Clin Exp Dermatol Res. 2012;3:157.

28. Dinno MA, Dyson M, Young SR, Mortimer AJ, Hart J, Crum LA. The significance of membrane changes in the safe and effective use of therapeutic and diagnostic ultrasound. Phys Med Biol. 1989; 34(11):1543-1552.

29. Jayasinghe S, Guillot T, Bissoon L, Greenway F. Mesotherapy for local fat reduction. Obesity Rev. 2013;14:780-791.

30. Palumbo P, Cinque B, Miconi G, et al. Biological effects of low frequency high intensity ultrasound application on ex vivo human adipose tissue. Int J Immunopathol Pharmacol. 2011;24(2):411-422.
31. Bani D, Quattrini Li A, Freschi G, Russo GL. Histological and ultrastructural effects of ultrasound-induced cavitation on human skin adipose tissue. Plast Reconstr Surg Glob Open. 2013;1(6):e41.

32. Franco W, Kothare A, Ronan SJ, Grekin RC, Mccalmont TH. Hyperthermic injury to adipocyte cells by selective heating of subcutaneous fat with a novel radiofrequency device: feasibility studies. Lasers Surg Med. 2010;42(5):361-370.

33. Kyriakou Z, Corral-Baques MI, Amat A, Coussios CC. Hifu-induced cavitation and heating in ex vivo porcine subcutaneous fat. Ultrasound Med Biol. 2011;37(4):568-579.

34. Brown SA, Rohrich RJ, Kenkel J, Young VL, Hoopman J, Coimbra M. Effect of low-level laser therapy on abdominal adipocytes before lipoplasty procedures. Plast Reconstr Surg. 2004;113(6):1796-1804.

35. Rose PT, Morgan M. Histological changes associated with mesotherapy for fat dissolution. J Cosmet Laser Ther. 2005;7(1):17-19.

36. Schuller-Petrovic S, Wölkart G, Höfler G, Neuhold N, Freisinger F, Brunner F. Tissue-toxic effects of phosphatidylcholine/deoxycholate after subcutaneous injection for fat dissolution in rats and a human volunteer. Dermatol Surg. 2008;34(4):529-542.

37. Thuangtong R, Bentow JJ, Knopp K, Mahmood NA, David NE, Kolodney MS. Tissue-selective effects of injected deoxycholate. Dermatol Surg. 2010;36(6):899-908.

38. Whittemore R, Knafl K. The integrative review: updated methodology. J Adv Nurs. 2005;52(5),546-553.

39. Salti G, Ghersetich I, Tantussi F, Bovani B, Lotti T. Phosphatidylcholine and sodium deoxycholate in the treatment of localized fat: a doubleblind, randomized study. Dermatol Surg. 2008;34(1):60-66.

40. Meyer PF, da Silva RM, Oliveira G, et al. Effects of cryolipolysis on abdominal adiposity. Case Rep Dermatol Med. 2016;2016:6052194.

41. Mahmoud Eldesoky MT, Mohamed Abutaleb EE, Mohamed Mousa GS. Ultrasound cavitation versus cryolipolysis for non-invasive body contouring. Australas J Dermatol. 2015;57:288-293.

42. Ingargiola MJ, Motakef S, Chung MT, Vasconez HC, Sasaki GH Cryolipolysis for fat reduction and body contouring: safety and efficacy of current treatment paradigms. Plast Reconstr Surg. 2015;135(6): 1581-1590.

43. Manstein D, Laubach H, Watanabe K, Farinelli W, Zurakowski D, Anderson RR. Selective cryolysis: a novel method of non-invasive fat removal. Lasers Surg Med. 2008;40(9):595-604.

44. Krueger N, Mai SV, Luebberding S, Sadick NS. Cryolipolysis for noninvasive body contouring: clinical efficacy and patient satisfaction. Clin Cosmet Investig Dermatol. 2014;7:201-205.

45. Hall TL, Lee GR, Cain CA, Hernandez-Garcia L. Relaxation properties of cavitation induced tissue lesions. Proc Intl Soc Mag Reson Med. 2007; $15: 1118$

46. Poon IK, Lucas CD, Rossi AG, Ravichandran KS. Apoptotic cell clearance: basic biology and therapeutic potential. Nat Rev Immunol. 2014;14(3):166-180.

47. Pugliese D, Maiorano E, Pascone M. Histopathological features of tissue alterations induced by low frequency ultrasound with cavitational effects on human adipose tissue. Int J Immunopathol Pharmacol. 2013;26(2):541-547.

48. Bechara FG, Georgas D, Sand M, Tomi N, Altmeyer P, Hoffmann K. Encapsulated fat necrosis after lipolysis of the calf with phosphatidylcholine. Dermatology. 2008;216(2):180-181.

49. Alcalá M, Sánchez-Vera I, Sevillano J, et al. Vitamin E reduces adipose tissue fibrosis, inflammation, and oxidative stress and improves metabolic profile in obesity. Obesity (Silver Spring). 2015;23(8): 1598-1606.

50. Pettersson AM, Acosta JR, Björk C, et al. Mafb as a novel regulator of human adipose tissue inflammation. Diabetologia. 2015;58(9): 2115-2123.

51. Prieur X, Mok CY, Velagapudi VR, et al. Differential lipid partitioning between adipocytes and tissue macrophages modulates macrophage lipotoxicity and $\mathrm{m} 2 / \mathrm{m} 1$ polarization in obese mice. Diabetes. 2011;60(3):797-809. 
52. Lumeng CN, Delproposto JB, Westcott DJ, Saltiel AR. Phenotypic switching of adipose tissue macrophages with obesity is generated by spatiotemporal differences in macrophage subtypes. Diabetes. 2008;57(12):3239-3246.

53. Mantovani A, Sica A, Sozzani S, Allavena P, Vecchi A, Locati M. The chemokine system in diverse forms of macrophage activation and polarization. Trends Immunol. 2004;25(12):677-686.

54. Cinti S, Mitchell G, Barbatelli G, et al. Adipocyte death defines macrophage localization and function in adipose tissue of obese mice and humans. J Lipid Res. 2005;46(11):2347-2355.

55. Lumeng CN, Bodzin JL, Saltiel AR. Obesity induces a phenotypic switch in adipose tissue macrophage polarization. $J$ Clin Invest. 2007;117(1):175-184.

56. Engelhardt E, Toksoy A, Goebeler M, Debus S, Bröcker EB, Gillitzer R. Chemokines Il-8, Groalpha, Mcp-1, Ip-10, and Mig are sequentially and differentially expressed during phase-specific infiltration of leukocyte subsets in human wound healing. Am J Pathol. 1998;153(6):1849-1860.

57. Singer AJ, Clark RA. Cutaneous wound healing. $N$ Engl J Med 1999;341(10):738-746.

58. Nguyen KD, Qiu Y, Cui X, et al. Alternatively activated macrophages produce catecholamines to sustain adaptive thermogenesis. Nature. 2011;480(7375):104-108.

59. Ricardo-Gonzalez RR, Red Eagle A, Odegaard JI, et al. Il-4/Stat6 immune axis regulates peripheral nutrient metabolism and insulin sensitivity. Proc Natl Acad Sci U S A. 2010;107(52):22617-22622.

60. Kim WS, Park BS, Sung JH, et al. Wound healing effect of adiposederived stem cells: a critical role of secretory factors on human dermal fibroblasts. J Dermatol Sci. 2007;48(1):15-24.

61. Nakajima I, Yamaguchi T, Ozutsumi K, Aso H. Adipose tissue extracellular matrix: newly organized by adipocytes during differentiation. Differentiation. 1998;63(4):193-200.

62. Rosenberg GJ, Cabrera RC. External ultrasonic lipoplasty: an effective method of fat removal and skin shrinkage. Plast Reconstr Surg. 2000;105(2):785-791.

63. Jalian HR, Avram MM, Garibyan L, Mihm MC, Anderson RR. Paradoxical adipose hyperplasia after cryolipolysis. Jama Dermatol. 2014;150(3):317-319.

64. Singh SM, Geddes ER, Boutrous SG, Galiano RD, Friedman PM. Paradoxical adipose hyperplasia secondary to cryolipolysis: an underreported entity? Lasers Surg Med. 2015;47(6):476-478.

65. Bechara FG, Sand M, Hoffmann K, Sand D, Altmeyer P, Stücker M. Fat tissue after lipolysis of lipomas: a histopathological and immunohistochemical study. J Cutan Pathol. 2007;34(7):552-557.
66. Jewell ML, Baxter RA, Cox SE, et al. Randomized sham-controlled trial to evaluate the safety and effectiveness of a high-intensity focused ultrasound device for noninvasive body sculpting. Plast Reconstr Surg. 2011;128(1):253-262.

67. Liu HL, Chen WS, Chen JS, Shih TC, Chen YY, Lin WL. Cavitationenhanced ultrasound thermal therapy by combined low- and highfrequency ultrasound exposure. Ultrasound Med Biol. 2006;32(5): 759-767.

68. Coleman KM, Coleman WP 3rd, Benchetrit A. Non-invasive, external ultrasonic lipolysis. Semin Cutan Med Surg. 2009;28(4):263-267.

69. Fatemi A, Kane MA. High-intensity focused ultrasound effectively reduces waist circumference by ablating adipose tissue from the abdomen and flanks: a retrospective case series. Aesthetic Plast Surg. 2010;34(5):577-582.

70. Song AY, Bennett JM, Marra KG, Cimino WW, Rubin JP. Scientific basis for the use of hypotonic solutions with ultrasonic liposuction. Aesthetic Plast Surg. 2006;30(2):233-238.

71. Garcia O Jr, Schafer M. The effects of nonfocused external ultrasound on tissue temperature and adipocyte morphology. Aesthet Surg J. 2013; 33(1):117-127.

72. Teitelbaum SA, Burns JL, Kubota J, et al. Noninvasive body contouring by focused ultrasound: safety and efficacy of the Contour I device in a multicenter, controlled, clinical study. Plast Reconstr Surg. 2007;120(3):779-789.

73. Jackson RF, Dedo DD, Roche GC, Turok DI, Maloney RJ. Low-level laser therapy as a non-invasive approach for body contouring: a randomized, controlled study. Lasers Surg Med. 2009;41(10):799-809.

74. Zelickson B, Egbert BM, Preciado J, et al. Cryolipolysis for noninvasive fat cell destruction: initial results from a pig model. Dermatol Surg. 2009;35(10):1462-1470.

75. Rzany B, Griffiths T, Walker P, Lippert S, McDiarmid J, Havlickova B. Reduction of unwanted submental fat with ATX-101 (deoxycholic acid), an adipocytolytic injectable treatment: results from a phase III, randomized, placebo-controlled study. Br J Dermatol. 2014;170(2): 445-453.

76. Palumbo P, Melchiorre E, La Torre C, et al. Effects of phosphatidylcholine and sodium deoxycholate on human primary adipocytes and fresh human adipose tissue. Int J Immunopathol Pharmacol. 2010;23(2): 481-489.

77. Pinto H, Hernandez C, Turra C, Manzano M, Salvador L, Tejero P. Evaluation of a new adipocytolytic solution: adverse effects and their relationship with the number of vials injected. J Drugs Dermatol. 2014; 13(12):1451-1455.
Clinical, Cosmetic and Investigational Dermatology

\section{Publish your work in this journal}

Clinical, Cosmetic and Investigational Dermatology is an international, peer-reviewed, open access, online journal that focuses on the latest clinical and experimental research in all aspects of skin disease and cosmetic interventions. This journal is included on PubMed. The manuscript management system is completely online

\section{Dovepress}

and includes a very quick and fair peer-review system, which is all easy to use. Visit http://www.dovepress.com/testimonials.php to read real quotes from published authors 